supervised administration as it is being adopted elsewhere.

In rural areas, such as Cornwall, providing supervised

original papers administration facilities (injecting rooms) is likely to prove prohibitively expensive, and having other safeguards in place that limit leakage of medications onto the black market may have to be sufficient. This could include an ampoule return scheme similar to the one we have developed, where pharmacists are paid to count returned ampoules before dispensing the next prescription. More guidance to commissioners is needed in this area.

In Cornwall we have also initiated a 'diamorphine panel', a special review clinic for patients on diamorphine attended by the prescribing consultants, the service manager and the service user coordinator. This was initiated when, for cost purposes, rationing of diamorphine was introduced in Cornwall over a year ago. The panel reviews individuals once a year, sets treatment goals and prescribes diamorphine to those most in clinical need.

Cost is still a big issue. Diamorphine continues to be far more expensive in the UK than Europe and supplies remain somewhat precarious despite the notable failure of supply that hit the UK in 2004/5 (White et al, 2005). These issues of paramount importance are ones that only the government can address, relating as they do to the legislative controls around opium refining and manufacture. Establishing the cost-effectiveness of injectable prescribing in the UK will hinge on this chronically unresolved issue and so for the foreseeable future guidance to clinicians and commissioners will remain unclear.

\section{Declaration of interest}

None.

\section{References}

LINTZERIS, N., STRANG, J., METREBIAN, N., et al (2006) Methodology for the Randomised Injecting Opioid Treatment Trial (RIOTT): evaluating injectable methadone and injectable heroin treatment versus optimised oral methadone treatment in the UK. Harm Reduction Journal, 3, 28

NATIONAL TREATMENT AGENCY FOR SUBSTANCE MISUSE (2003) Injectable Heroin (and Injectable Methadone): Potential Roles in Drug Treatment. National Treatment Agency for Substance Misuse.

PERNEGER, T.V., GINER, F., DEL RIO, M., et al (1998) Randomised trial of heroin maintenance programme for addicts who fail conventional drug treatments. $B M J, 317,13-18$

SELL, L. \& ZADOR, D. (2004) Patients prescribed injectable heroin or methadone - their opinions and experiences of treatment. Addiction 99, 442-449.

STRANG, J. \& GOSSOP, M. (1994) Heroin Addiction and Drug Policy: The British System. Oxford University Press.

STRANG, J., SHERIDAN, J. \& BARBER, N. (1996) Prescribing injectable and oral methadone to opiate addicts: results from the 1995 national postal survey of community pharmacies in England and Wales. BMJ, 313, 270-272.

THE GUARDIAN (2005) Closed for Business. Tuesday 10 May. Guardian News and Media.

VANDEN BRINK, W., HENDRICKS, V. M. BLANKEN, P., et al (2002) Medical CoPrescription of Heroin: Two

Randomised Controlled Trials. Central Committee on the Treatment of Heroin Addicts.

WHITE, R., COX, D. \& CHARNAUD, B. (2005) Lessons from the ongoing UK injectable diamorphine shortage. Addiction, 100, 1741-1742.

ELEANOR TIANGGA，ASHA GOWDA AND JOHN A. DENT

\title{
Vitamin D deficiency in psychiatric in-patients and treatment with daily supplements of calcium and ergocalciferol
}

\author{
AIMS AND METHOD \\ This study examines the prevalence of \\ vitamin D deficiency in a group of \\ male psychiatric in-patients and \\ follows 16 of them prospectively \\ during treatment with calcium and \\ ergocalciferol tablets. \\ RESULTS \\ Of 17 male patients, 15 had vitamin D \\ deficiency and two had borderline \\ deficiency. Vitamin D deficiency was
}

associated with Black and minority ethnic background. Improvement in vitamin D status was observed following replacement therapy.

\section{CLINICAL IMPLICATIONS}

Vitamin D deficiency may be widespread in the psychiatric population particularly in Black and minority ethnic but also in White European in-patients. Vitamin D level should be routinely monitored in psychiatric

\begin{abstract}
in-patients. For those with vitamin D deficiency, replacement therapy can be commenced with calcium and ergocalciferol tablets (containing $10 \mu \mathrm{g}$ of ergocalciferol), which is safe and well tolerated. All psychiatric in-patients should have adequate exposure to sunlight and attention to diet to ensure that they receive their recommended daily allowance of vitamins and minerals.
\end{abstract}

The main source of vitamin $D$ is from ultraviolet- $B$ radiation on the skin. It is also obtained from foods such as fish, eggs, dairy products and fortified margarine or cereals. Sunlight deprivation is more important than inadequate nutrition as a cause of vitamin $D$ deficiency and therefore failure to spend time outdoors, covering up 
with clothes or the use of sunscreens results in decreased skin synthesis of vitamin D.

Other secondary causes of vitamin D deficiency are malabsorption, the use of anticonvulsants, such as carbamazepine and phenytoin, and hepatic and renal disorders, which affect vitamin D metabolism. Risk factors for vitamin D deficiency also include obesity, although the reason is unclear, and pigmented skin, which filters out ultraviolet-B radiation involved in the production of vitamin $\mathrm{D}$.

Vitamin D deficiency has been well documented in older people, especially among those living in institutions. In a population survey that sampled the vitamin $D$ levels of 1766 people over the age of 65 , the prevalence of vitamin $D$ deficiency in those living in institutions was over $30 \%$ compared with $9.6 \%$ of men and $15 \%$ of women living in private households (Hirani \& Primatesta, 2005). More recently, vitamin D deficiency has been reported in psychiatric patients. A programme developed in a residential community in Australia including complete health assessments for all residents found that out of 30 residents tested, 3 had vitamin D levels in the normal range, 20 in the deficient range and 7 in the severely depleted range (Howard et al, 2006).

\section{Method}

25-hydroxycholecalciferol (25OHD) is the best indicator of vitamin D status. However, there is no generally accepted criterion for vitamin D deficiency. Some specialists suggest that $25 \mathrm{OHD}$ has to be above $50 \mathrm{nmol} / \mathrm{l}$ for people to have true vitamin D sufficiency and for all the parameters of calcium metabolism to be normal. For the psychiatric in-patients in this study, the normal range of $250 \mathrm{HD}$ was $25-120 \mathrm{nmol} / \mathrm{l}$. Concentrations below $25 \mathrm{nmol} / \mathrm{I}$ are consistent with vitamin D deficiency, which may be associated with osteomalacia (Anonymous, $2006 a, 2006 b$ ). For the purpose of this study, 25OHD levels in the range $25-50 \mathrm{nmol} / /$ were taken to indicate borderline deficiency.

\section{Study setting and patient population}

The patient population is based in a low secure psychiatric service where individuals are referred for rehabilitation from acute adult wards, psychiatric intensive care units and prisons in West London. For security reasons, some in-patients have limited freedom to leave the unit without a nurse escorting them, and constraints on nursing numbers mean this is not always feasible. The average length of admission is in excess of 1 year.

Initially, vitamin D status was queried in two inpatients: one had gait disturbance and a history of peritoneal tuberculosis, the other was taking the anti-obesity drug orlistat which can affect absorption of fat-soluble vitamins. To quantitatively determine $250 \mathrm{HD}$ we used 25-Hydroxy Vitamin D kit (Immunodiagnostic Systems, Boldon, Tyne and Wear, UK; www.idsltd.com/), which is a conventional liquid phase radioimmunoassay. These two individuals were both found to have $250 \mathrm{HD}$ levels in the deficient range $(<25 \mathrm{nmol} / \mathrm{l})$. As low vitamin $D$ levels can be associated with activation of latent tuberculosis, and there had been three cases of tuberculosis on the ward in the previous 18 months, other in-patients with a history of active or latent tuberculosis were then investigated. After finding consistently low levels of $250 H D$ in these in-patients, all the individuals coming into the service were offered vitamin D tests as part of their routine blood monitoring.

The study population consisted of males aged 24-53 years old. At the start of the study, out of 18 in-patients, 17 agreed to have blood samples taken as part of their routine care. Calcium and ergocalciferol (calcium and vitamin D) tablets containing $10 \mu \mathrm{g}(400$ units) ergocalciferol and calcium $97 \mathrm{mg}$ are available for use as a daily supplement. A higher ('pharmacological') strength ergocalciferol formulation containing $250 \mu \mathrm{g}$ (10 000 units) ergocalciferol is available but necessitates regular monitoring for hypercalcaemia. A decision to use the lower strength preparation was made on the basis that this would be safer, given the potential for cardiac arrhythmias was already raised in this patient population owing to the use of antipsychotic drugs and that frequent checking for hypercalcaemia would be impractical.

In this study, the lower strength daily supplement $(10 \mu \mathrm{g}$ ergocalciferol) at a dose of one tablet daily was offered to in-patients with $250 \mathrm{OHD}$ levels lower than $25 \mathrm{nmol} / \mathrm{l} ; 25 \mathrm{OHD}$ test levels were repeated after approximately 7 months ( mean $=19$, s.d. $=82$ ).

\section{Results}

Of the 17 in-patients who had a blood test performed, none had vitamin D sufficiency using the strictest criteria. Two individuals had 250HD levels in the range 25$50 \mathrm{nmol} / \mathrm{I}$ indicating borderline deficiency. For the other 15 individuals, vitamin $D$ levels were below $25 \mathrm{nmol} / \mathrm{l}$, including 7 people whose 25OHD level was below $17.5 \mathrm{nmol} / \mathrm{l}$ (i.e. below the level for which the test can provide an accurate quantitative result).

Of the 17 in-patients in the study, 10 were African or African-Caribbean, 2 were of mixed ethnicity (AfricanCaribbean/White European), 1 was Vietnamese and 4 were White European. For analysis by ethnicity the ethnic groups were collapsed into White or Black and minority ethnic groups. All the Black and minority ethnic group inpatients were found to have $250 \mathrm{HD}$ levels in the deficient range (below $25 \mathrm{nmol} / \mathrm{l}$ ); of the 4 White European in-patients, 2 had deficiency and 2 had borderline deficiency. The difference between the White and Black and minority ethnic groups was significant using twotailed Fisher's exact test $(P=0.044)$.

In 12 in-patients who received treatment and in whom repeat measures were performed, an improvement in the $250 \mathrm{OHD}$ level was noted $(P<0.01$, paired t-test) in all but 1 patient (Fig. 1); 8 patients moved into the borderline deficiency range ( $25 \mathrm{OHD} 25-50 \mathrm{nmol} / \mathrm{l})$ but no one moved into the sufficient range $(25 \mathrm{OHD}>50 \mathrm{nmol} / \mathrm{l})$. Patients reported no adverse sideeffects during treatment with calcium and ergocalciferol. 


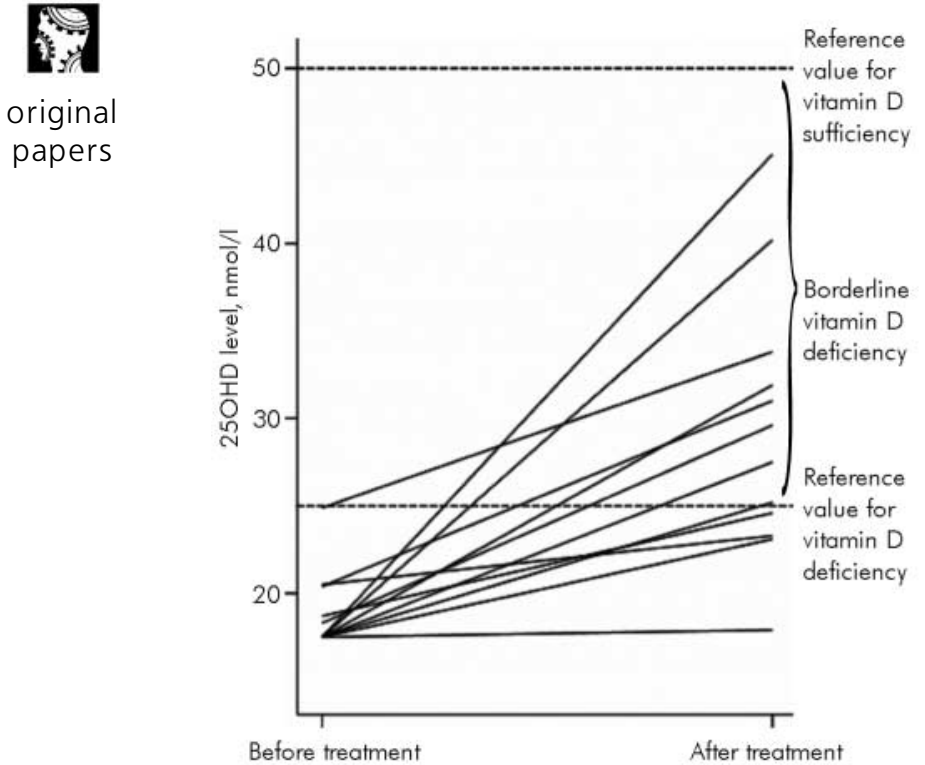

Fig. 1. Vitamin D (25OHD) levels before and after treatment.

There was no significant difference in repeat $250 \mathrm{HD}$ levels in four patients who did not receive treatment and who were tested again after an average interval of 105 days. This group included two recently admitted patients, whose $25 \mathrm{OHD}$ level dropped during the study, and one patient who went on leave to a hostel, whose $250 \mathrm{HD}$ level improved.

\section{Discussion}

The principal finding in the present case series was that 15 of the 17 long-stay psychiatric in-patients had evidence of vitamin $D$ deficiency using the most demanding criterion $(25 \mathrm{OHD}<25 \mathrm{nmol} / \mathrm{l})$ and none met the strictest criteria for vitamin $D$ sufficiency $(25 \mathrm{OHD}>50 \mathrm{nmol} / \mathrm{l})$.

\section{Effects of vitamin D deficiency}

Vitamin D regulates calcium and phosphate absorption and metabolism. Monitoring of serum calcium, phosphate and alkaline phosphatase may be helpful in diagnosing vitamin D deficiency, but although levels of alkaline phosphatase may increase early in vitamin D deficiency, calcium and phosphate may only fall in long-standing, symptomatic vitamin D deficiency (Anonymous, 2006b).

Vitamin $D$ deficiency has long been associated with bone diseases such as rickets in children and osteomalacia and osteoporosis in adults as the result of inadequate mineralisation of the bone matrix. It is also one of the causes of hypocalcaemia.

More recently, vitamin $D$ has been noted to have more widespread effects on health. It appears to play an important role in muscle function - most individuals with vitamin $D$ deficiency who present clinically do so because of muscle weakness or muscle pain (Anonymous, 2006b). Studies have also shown that deficiency of vitamin $D$ is associated with a reduction in grip strength and that its supplementation in older people reduced the incidence of fractures by improving neuromuscular function (Grant, 2006). Vitamin $D$ has also been associated with reduction in the risk of specific cancers - the evidence that it reduces the risk of cancer is strongest for colon cancer, based on ecologic case-control cohort and laboratory studies (Grant, 2006). The evidence is also strong for lung cancer and there is reasonable evidence for other cancers including breast, ovarian, prostate, rectal and nonHodgkin lymphoma (Grant, 2006). There is increasing evidence that vitamin $D$ reduces both the risk of development and severity of symptoms of multiple sclerosis and that it reduces the risk of type 1 diabetes.

There is weaker evidence that vitamin D deficiency is associated with rheumatoid arthritis, osteoarthritis, type 2 diabetes, hypertension and cardiovascular disease (Grant, 2006). Vitamin D deficiency also commonly associates with tuberculosis. In a study in West London, vitamin $\mathrm{D}$ deficiency was associated with active tuberculosis and undetectable levels of 250HD carried a higher risk of tuberculosis among Gujarati Asians (Wilkinson et al, 2000). Another study in London showed that vitamin $\mathrm{D}$ deficiency commonly associates with tuberculosis among all ethnic groups apart from White Europeans and Chinese or South East Asians (Ustianowski et al, 2005).

\section{Vitamin D and mental health}

Psychiatric in-patients may be particularly vulnerable to vitamin $D$ deficiency because of lack of exposure to sunlight, poor dietary habits, the use of anticonvulsants and overrepresentation of ethnic groups known to be at greater risk. Individuals with psychiatric problems often have poor physical health and many of the problems which are associated with vitamin D deficiency compound existing medical morbidity in this group.

Similar epidemiology of vitamin D deficiency and schizophrenia has led some authors to suggest that low vitamin D levels can themselves predispose people to mental disorders. A study looking at a birth cohort from Northern Finland found use of vitamin D supplements in the first year of life was associated with a reduced risk of developing schizophrenia in later life in males but not females (McGrath et al, 2004). However, initial studies looking for association between polymorphisms of the vitamin $\mathrm{D}$ receptor and risk of schizophrenia have been negative (Handoko et al, 2006).

\section{Limitations of the study}

Our study was prompted by the chance finding of vitamin $D$ deficiency in our patients. There is no control group and it is difficult to know whether the results could be generalised to in-patients in other settings. The sample size is too small to indicate whether the fall in vitamin D levels correlates with length of admission to hospital and is therefore something specific to the hospital milieu (e.g. lack of sunlight, poor nutrition or medication). Tests on two recently admitted patients show normal levels that drop within the first 2 months but this needs further 
investigation. Further investigation is also required to find the optimum dosing regime to return $25 \mathrm{OHD}$ levels to normal and to find out how long such treatment needs to continue.

\section{Implications}

Vitamin D should be routinely monitored in psychiatric inpatients as it appears they are a group at increased risk of deficiency. Replacement therapy can be commenced with calcium and ergocalciferol tablets (containing $10 \mu \mathrm{g}$ of ergocalciferol), which produce a significant rise to at least borderline deficiency in most patients. Further study is required to clarify optimal dosing and whether this should be continued until patients are in the sufficient range.

All psychiatric in-patients should have adequate exposure to sunlight and this should be taken into consideration when reviewing leave policies and access to outdoor facilities such as secure gardens or balconies. Already there has been much consideration given to the development of metabolic syndrome in psychiatric patients and regulation of hospital food and dietary advice. Close attention to diet is essential to ensure that psychiatric in-patients also receive their recommended daily allowance of all vitamins and minerals, including vitamin D. The widespread vitamin D deficiency among psychiatric in-patients in this study highlights the need for comprehensive primary healthcare to be provided for this patient group.

\section{Declaration of interest}

None.

\section{Acknowledgements}

We thank Gary Baxter, Professor of Pharmacology at the University of Cardiff, Richard Ball, Dietician at the West London Mental Health NHS Trust, and Mandy Donaldson, Principal Biochemist at the Hammersmith Hospital, London.

\section{References}

ANONYMOUS (2006a) Primary vitamin HOWARD, D. A., WAYGOOD, S. D. \& D deficiency in children. Drug and DESMOND, S. L. (2006) Vitamin D and Therapeutics Bulletin, 44,6-12. chronic mental illness. Medical Journal ANONYMOUS (2006b) Primary vitamin of Australia, 184, 47

$D$ deficiency in adults. Drug and Therapeutics Bulletin, 44, 25-29.

GRANT,W. B. (2006) Epidemiology of disease risks in relation to vitamin D insufficiency. Progress in Biophysics and Molecular Biology, 92, 65-79.

HANDOKO, H.Y., NANCARROW, D. J., MOWRY, B. J., et al (2006)

Polymorphisms in the vitamin D receptor and their associations with risk of schizophrenia and selected anthropometric measures. American Journal of Human Biology, 18, 415-417.

HIRANI, V. \& PRIMATESTA, P. (2005) Vitamin $D$ concentrations among people aged 65 years and over living in private households and institutions in England: population survey. Age and Ageing, 34, 485-491.

McGRATH, J., SAARI, K., HAKKO, H., et al (2004) Vitamin D supplementation in the first year of life and risk of schizophrenia: a Finnish birth cohort study. Schizophrenia Research, 67, 237-245.

USTIANOWSKI, A., SHAFFER, R.

COLLIN, S., et al (2005) Prevalence and associations of vitamin $\mathrm{D}$ deficiency in foreign-born persons with tuberculosis in London. Journal of Infection, 50, 432-437.

WILKINSON, R. J., LLEWELYN, M. TOOSSI, Z., et al (2000) Influence of vitamin $D$ deficiency and vitamin $D$ receptor polymorphisms on tuberculosis among Gujarati Asians in west London: a case-control study. Lancet, 355, 618-621.

EleanorTiangga Specialist TraineeYear 3, Asha Gowda Specialist Trainee Year 3, *John A. Dent Consultant Psychiatrist, St Bernards Hospital, 2nd floor, Tony HillisWing, Southall, Middlesex UB13EU, email: john.dent@wlmht.nhs.uk original

papers 